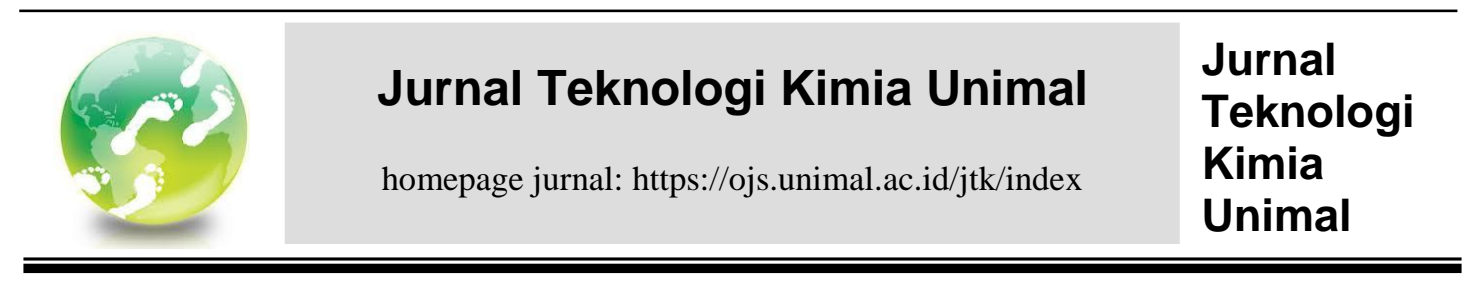

\title{
PENGARUH TEMPERATUR DAN WAKTU PEMASAKAN TERHADAP PEROLEHAN MINYAK KEMIRI DENGAN MENGGUNAKAN CARA BASAH
}

Sulhatun, Mutiawati, Eddy Kurniawan

Jurusan Teknik Kimia, Fakultas Teknik, Universitas Malikussaleh

Kampus Utama Cot Teungku Nie Reuleut, Muara Batu, Aceh Utara - 24355

Korespondensi: e-mail: Mutiawati1201@gmail.com

\begin{abstract}
Abstrak
Kemiri merupakan buah paling banyak manfaat bagi kesehatan manusia. Selain daging buahnya yang dapat dikonsumsi, Kemiri (Aleurites moluccana), adalah tumbuhan yang bijinya dimanfaatkan sebagai sumber minyak dan rempahrempah Buah kemiri juga diyakini berkhasiat mengobati buang air besar yang berdarah, diare, disentri, sakit perut, sembelit, demam, sariawan, dan sakit gigi. Kemiri mengandung zat gizi dan nongizi. Zat nongizi dalam kemiri misalnya saponin, falvonoida, dan polifenol.Pada penelitian ini dilakukan proses pemasakan, dimana dilakukan analisa persen rendemen, dan analisa berat jenis dari hasil minyak kimiri. Tujuan dari penelitian ini adalah mengetahui pengaruh variasi waktu pemasakan biji kemiri terhadap rendemen minyak yang dihasilkan. Penelitian ini dilakukan dengan cara pada suhu $65^{\circ} \mathrm{C}, 70^{\circ} \mathrm{C}$ dan $75^{\circ} \mathrm{C}$. Dimana berat kemiri $1 \mathrm{~kg}$, serta divariasikan waktu 85 menit, 115 menit, dan 145 menit. Hasil penelitian menunjukkan bahwa rendemen minyak kemiri terbesar adalah $47 \%$ pada waktu 145 menit dan suhu $75^{\circ} \mathrm{C}$. dan densitas yang tinggi yaitu 0,87 $\mathrm{gr} / \mathrm{ml}$ pada suhu $75^{\circ} \mathrm{C}$ dan waktu selama 145 menit.

Kata kunci: pemasakan, minyak kemiri,densitas dan rendemen
\end{abstract}

\section{Pendahuluan}

Kemiri (Aleurites moluccana) adalah salah satu tanaman industri yang tersebar di daerah yang tropis dan subtropis (Atjung,1982). Kemiri merupakan tanaman asli hawai dan saat ini banyak tumbuh secara alami di indonesia. Produksi kemiri di indonesia cukup besar yaitu mencapai 88.481 ton/tahun dimana produksi tersebut mengalami peningkatan tiap tahunnya. (Rosman dan Djauhariya, tanpa tahun).

Tanaman kemiri merupakan banyak manfaat bagi kehidupan manusia, karena hampir semua bagian tanaman dapat digunakan, namun bagian tanaman yang memiliki nilai ekonomi tinggi adalah biji kemiri. Biji kimiri dapat digunakan 
Sulhatun, Mutiawati, Eddy Kurniawan / Jurnal Teknologi Kimia Unimal $9: 2$ (November 2020) $41-48$

sebagai bumbu masak, obat, kosmetik, dan sebagainya. Salah satu cara umtuk memanfaatkan biji kemiri adalah dengan mengekstraksi biji kemiri memiliki kadar minyak yang tinggi, yaitu sekitar 35\%-65\% minyak. (Ketaren, 1986).

Kandungan Kimia daging biji, daun dan akar Aleurites moluccana mengandung saponin, flavonoida dan polifenol, di samping itu daging bijinya mengandung minyak lemak. Pada korteksnya mengandung tannin (Anonym,1997). Kegunaan dan Khasiat daging bijinya bersifat laksatif. Di Ambon korteksnya digunakan sebagai anti tumor (Harini, 2000), di Jawa digunakan sebagai obat diare, sariawan dan desentri, di Sumatera daunnya digunakan untuk obat sakit kepala dan gonnorhea. Minyak kemiri dibuktikan berkhasiat sebagai obat penumbuh rambu.

Tabel 2.2 Sifat kimia dan fisika minyak kemiri

\begin{tabular}{|l|l|l|}
\hline No & \multicolumn{1}{|c|}{ Parameter } & \multicolumn{1}{|c|}{ Persyaratan } \\
\hline 1. & FFA (\%) & $0,10-1,50$ \\
\hline 2. & Bilangan io dine (g 12/100 g sampel) & $136-167$ \\
\hline 3. & Bilangan penyambunan (mh KOH/g sampel) & $184-202$ \\
\hline 4. & Warna & Normal \\
\hline 5. & Densitas & $0,9240-0,9290$ \\
\hline 6. & Indeks bias & $1,4730-14790$ \\
\hline
\end{tabular}

\section{Bahan dan Metode}

Bahan yang digunakan pada penelitian ini adalah biji kemiri dan air. Mrtode pertama proses adalah ekstraksi biji kemiri, tahap kedua uji distilasi dan tahap ketiga analisa rendemen, berat jenis (densitas), danuji GCMS. Variabel tetapyang digunakan adalah berat biji kemiri 1000 gr, suhu ekstraksi $65{ }^{\circ} \mathrm{C}$, suhu $70{ }^{\circ} \mathrm{C}, 75$ ${ }^{0} \mathrm{C}$.

Waktu ekstraksi: 85 menit, 115 menit, dan 145 menit. 


\section{Hasil dan Diskusi}

\subsection{Pengaruh waktu dan volume pelarut terhadap rendemen}

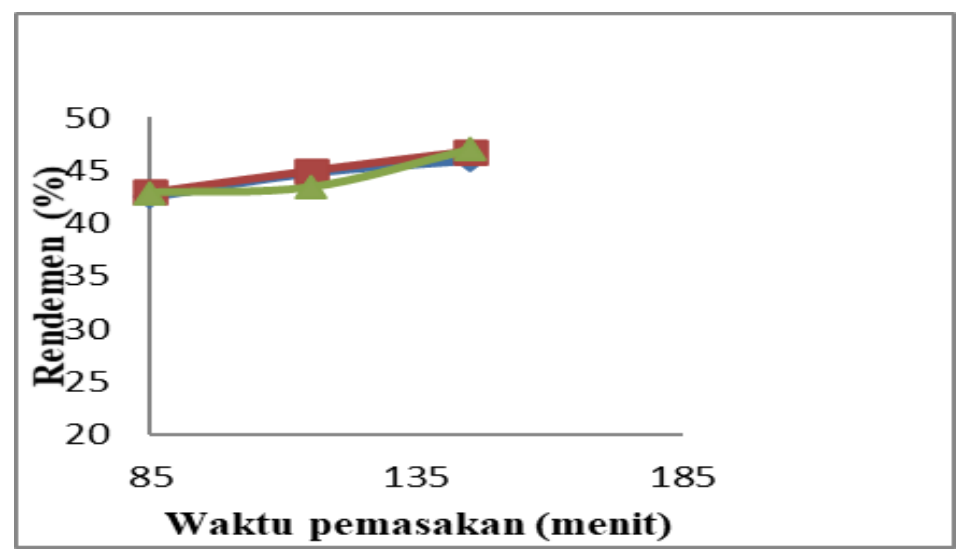

Gambar 1. Pengaruh Waktu Ektraksi dan Volume Pelarut Terhadap Persen Rendemen Minyak kemiri

Dari Gambar 3.1 dapat dilihat bahwa waktu pemasakan dan suhu yang digunakan sangat mempengaruhi \% rendemen minyak yang dihasilkan dari kemiri dengan metode ekstraksi. Hal ini dapat dijelaskan bahwa untuk mendapatkan kandungan minyak yang lebih banyak, diperlukan waktu pemasakan yang lebih lama pula agar terjadi waktu kontak yang lama antara kemiri dengan pelarut yang memberikan kesempatan kemiri untuk kontak dengan pelarut semakin besar sehingga kandungan minyak dapat diekstrak secara maksimum.

Pada waktu pemasakan yang tetap dengan peningkatan perbandingan pelarut terhadap kemiri menyebabkan kandungan minyak meningkat. Hal ini dapat dijelaskan bahwa pelarut harus banyak tersedia selama proses pemasakan agar dapat memaksimalkan kandungan minyak yang diekstrak. Semakin banyak pelarut yang digunakan, maka akan mengurangi tingkat kejenuhan.

Hasil terbaik yang didapat adalah pada suhu $75^{\circ} \mathrm{C}$ dengan waktu 145 menit, dimana $\%$ rendemen yang dihasilkan yaitu $47 \%$, dan rendemen yang paling rendah pada suhu $60^{\circ} \mathrm{C}$ dengan waktu 85 menit, dimana $\%$ rendemen yang dihasilkan yaitu 42,5. Hal ini menunjukkan bahwa semakin lama waktu pemasakan maka semakin tinggi \% rendemen minyak yang dihasilkan, dikarenakan semakin lama waktu ekstraksi maka pengontakan yang terjadi antara 
Sulhatun, Mutiawati, Eddy Kurniawan / Jurnal Teknologi Kimia Unimal 9 :2 (November 2020) $41-48$

bahan dengan pelarut berlangsung lama, sehingga kandungan minyak yang ada pada bahan akan banyak terekstrak dalam pelarut.3.2 Pengaruh Degree of Swelling terhadap Fluks Permeasi

\subsection{Pengaruh Waktu dan Volume Pelarut terhadap Densitas Minyak}

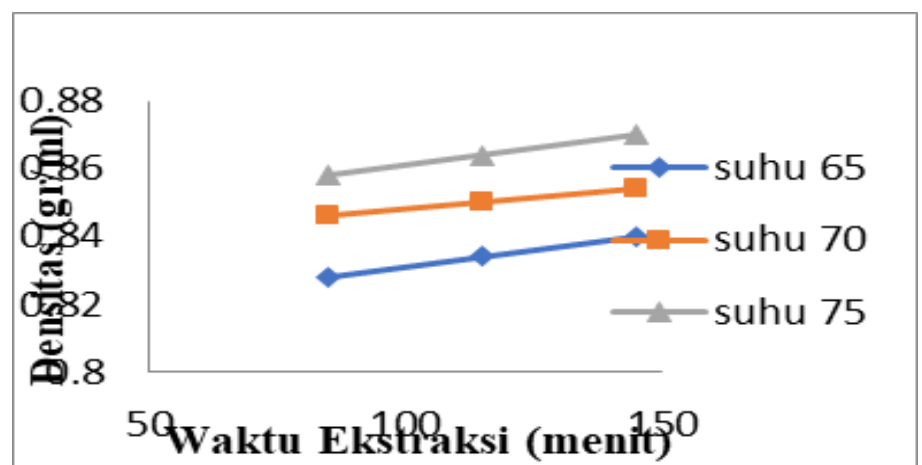

Gambar 2. Pengaruh Waktu dan Volume Pelarut terhadap Densitas Minyak

Dari Gambar 3.2 dapat dilihat untuk analisa berat jenis yang diperoleh berbeda-beda berdasarkan lama waktu ekstraksi dan suhu. Berat jenis menjelaskan banyaknya komponen yang terkandung dalam zat tersebut. Menurut Simbolon (2012), besar kecilnya nilai berat jenis sering dihubungkan dengan fraksi berat komponen-komponen yang terkandung didalamnya. Maka dari itu, apabila semakin besar fraksi berat yang terkandung dalam minyak, maka semakin besar pula nilai berat jenisnya. Adapun nilai berat jenis yang terbesar adalah hasil pemasakan dengan suhu $75\left({ }^{0} \mathrm{C}\right)$ dan waktu selama 145 menit, yaitu sebesar 0,87 gr/ml, sedangkan berat jenis yang terendah didapat pada suhu pemasakan $60\left({ }^{0} \mathrm{C}\right)$ selama 85 menit yaitu, $0,828 \mathrm{gr} / \mathrm{ml}$.

Semakin lama waktu pemasakan maka semakin tinggi berat jenis minyak kemiri yang didapat. Nilai berat jenis cenderung naik dengan bertambahnya suhu. Hal ini dikarenakan semakin lama waktu pemasakan dan semakin tinggi suhu maka densitas minyak yang dihasilkan semakin banyak komponen yang terekstraksi dari dalam kemiri sehingga menaikkan nilai berat jenisnya. Jadi dapat 
Sulhatun, Mutiawati, Eddy Kurniawan / Jurnal Teknologi Kimia Unimal 9 :2 (November 2020) $41-48$

dikatakan bahwa semakin lama waktu dan semakin besarnya suhu maka semakin tinggi berat jenis yang di dapat.

\subsection{Analisa Komposisi Minyak Biji Pepaya dengan GC-MS (Gas Chromatography Mass Spectrofotometry)}

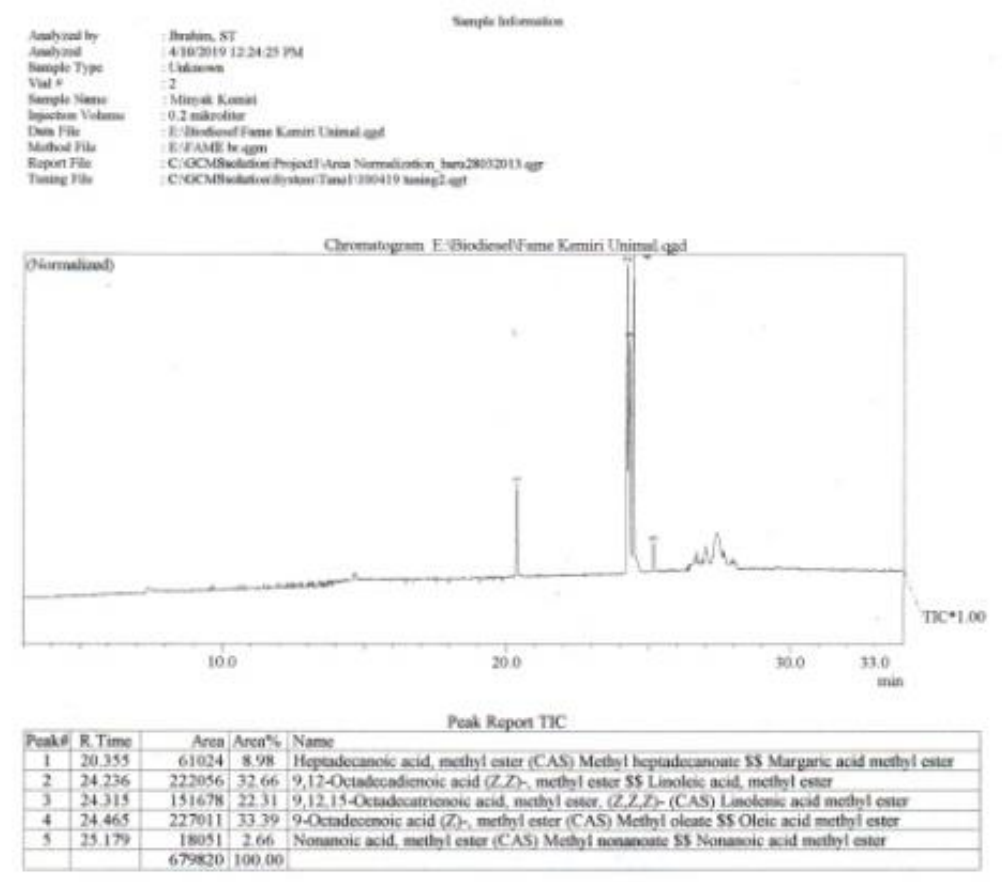

Gambar 3. Grafik Analisa Uji gc-ms

Gas Chromatography Mass Spectrofotometry berfungsi untuk mengetahui kandungan pada minyak kemiri. Adapun nilai GC-MS dapat dilihat dari Gambar 4.3. Identifikasi komponen-komponen kemiri menggunakan Gas Cromatografy Mass Spectrometry (GC-MS) dapat dilihat pada Gambar 4.3. Hasil GC-MS lima komponen utama pada minyak kemiri, diperoleh Heptadeconic acid, ethyl ester (CAS) Methyl heptadecanoate \$\$ Margaric acid methyl ester sebesar $8.98 \%$ pada waktu reserensi 20, 354 menit. 9,12-Octadecadienoic acid (Z,Z)-, methyl 
Sulhatun, Mutiawati, Eddy Kurniawan / Jurnal Teknologi Kimia Unimal $9: 2$ (November 2020) $41-48$

ester \$ \$Linoleic Acid, Methy esternsebesar 32,66 \% pada waktu reserensi 24,236 menit, 9,12,15-Octadecenoic acid, methyl ester (Z,Z,Z)- (CAS) Linolenic acid methyl ester sebesar $22.31 \%$ pada waktu reserensi 24.315 menit, 9- Octadecanoic acid (Z)-, methyl ester (CAS) Methyl oleate \$\$ Oleic acid methyl ester sebesar $33.39 \%$ pada waktu reserensi 24.465 menit. Nonanoic acid, methyl ester (CAS) methyl nonanoate \$ Nonanoic acid methyl ester sebesar $2.66 \%$ pada waktu reserasi 25.179 menit.

Kandungan metil ester terbesar yang diperoleh yaitu metil oleat dengan presentase area sebesar $33.39 \%$ pada waktu reserensi 24,465 menit, ini menunjukkan minyak kemiri mengandung asam oleat. Asam oleat mempunyai rumus kimia $\mathrm{C} 18 \mathrm{H} 34 \mathrm{O} 2$ dan merupakan fatty acid memiliki satu ikatan ganda. Asam oleat yang di dapat pada minyak kemiri dalam penelitian ini lebih tinggi jika dibandingkan dengan penelitian yang terdahulu yang menggunakan pelarut petroleum ether dengan presentase asam oleat sebesar 31,30\% (Malacrida, dkk, 2010).

\section{Simpulan dan Saran}

1. Variasi waktu dan suhu berpengaruh terhadap rendemen minyak yang dihasilkan. Pemasakan pada menit ke-145 dengan suhu $75\left({ }^{\circ} \mathrm{C}\right)$, dan Semakin lama waktu Pemasakan maka semakin tinggi berat jenis minyak kemiri serta semakin besar persen rendemen yang didapatkan.

2. Semakin tinggi suhu maka semakin tinggi berat jenis dan rendemen yang di dapatkan.

3. Berat jenis yang diperoleh pada menit ke-145 dengan suhu $75\left({ }^{0} \mathrm{C}\right)$ adalah $0,87(\mathrm{gr} / \mathrm{ml})$. 
Sulhatun, Mutiawati, Eddy Kurniawan / Jurnal Teknologi Kimia Unimal 9 :2 (November 2020) $41-48$

4. Rendemen minyak kemiri yang tertinggi didapat menit ke-145 dengan suhu $75\left({ }^{0} \mathrm{C}\right)$ adalah $47 \%$.

Penelitian ini dapat dilanjutkan dengan mengamati proses dehidrasi senyawa turunan atau derivat senyawa alkohol yang lebih nonpolar yang banyak digunakan dalam industri seperti isopropanol dan butanol.

\section{Daftar Pustaka}

Ketaren, S. 2008. Pengantar Teknologi Minyak dan Lemak Pangan. Jakarta: penerbit Universitas Indonesia (UI-Press).

Khopkar, S. M. 1990. Konsep Dasar Kimia Analitik. Jakarta: Penerbit Universitas Indonesia. Hal. 216-217.

Malacrida Roberta Cassia., Kimura Mieko.,dan Jorge Neuza. 2010. "Characterization of a high oleic oil extracted from papaya (Carica papaya L.) seeds". Department of Food Engineering and Technology, São Paulo State University - UNESP. Vol: 31(4), pp : 929-934.

Midian, S, 2014. Melirik Peluang Budaya Kemiri. http://www.jurnalisia.com/2014/02/19/15803/, 9 juli 2015.

Milind Parle and Gurditta. 2011."Basketful Benefits Of Papaya". International Research Journal Of Pharmacy, vol 2(7), pp : 6-12

Mulja, M., H. 1994. Perkembangan Instrumentasi Kromatografi Gas. Surabaya: Universitas Airlangga.

Oynlola, A., Ojo, A., Adekoya, L.O., 2004. Development of a laboratory model screw press for peanut oil expression. Jurnal of food engineering 64, 221-227.

Qomariyyah, S. 2012. Kemiri

http://salsaqomariyyah.blogspot.com/2012/10/kemiri-aleurites-

moluccana-iwild.html, 9 juli 2015.

Romadhon, A, F, 2014 Kemiri (Aleurites Moluccana)

Http://ccrc.farmasi.ugm.ac.id/?page_id=121, 5 juli 2015

Santoso, H., Iryanto, dan Inggrid, M. 2014 Effects of Temperature, Pressure, Preheating time and Pressing Time on Rubber Seed Oil Extraction Using Hydraulic Press. Procedia Chemistry.

Syed H.M., Kunte S.P., Jadhav B.A., dan Salver R.V. 2012."Extraction End Charactization Of Papaya Seed Oil". International Journal Of Applied, Physical And Bio-Chemistry Research Vol.2, pp: 33-43.

Winarmo, F. G. 1991. Kimia Pangan dan Gizi Jakarta: PT Gramedia Pustaka Utama

Www. Pusat Budidaya com,2011. Potensi Minyak Kemiri

Yazid, E. 2005. Kimia Fisika Untuk Paramedis. Yogyakarta: ANDI 